\title{
Observation management of pulmonary embolism and agreement with claims-based and clinical risk stratification criteria in United States patients: a retrospective analysis
}

\author{
Elaine Nguyen ${ }^{1}$, Craig I. Coleman ${ }^{1 *}$, W. Frank Peacock ${ }^{2}$, Philip S. Wells ${ }^{3}$, Erin R. Weeda', Veronica Ashton ${ }^{4}$, \\ Concetta Crivera ${ }^{4}$, Peter Wildgoose ${ }^{4}$, Jeff R. Schein ${ }^{4}$, Thomas J. Bunz ${ }^{5}$ and Gregory J. Fermann ${ }^{6}$
}

\begin{abstract}
Background: Guidelines suggest observation stays are appropriate for pulmonary embolism (PE) patients at low-risk for early mortality. We sought to assess agreement between United States (US) observation management of PE and claims-based and clinical risk stratification criteria.

Methods: Using US Premier data from 11/2012 to 3/2015, we identified adult observation stay patients with a primary diagnosis of $\mathrm{PE}, \geq 1 \mathrm{PE}$ diagnostic test claim and evidence of $\mathrm{PE}$ treatment. The proportion of patients at high-risk was assessed using the In-hospital Mortality for PulmonAry embolism using Claims daTa (IMPACT) equation and high-risk characteristics (age > 80 years, heart failure, chronic lung disease, renal or liver disease, high-risk for bleeding, cancer or need for thrombolysis/embolectomy).
\end{abstract}

Results: We identified 1633 PE patients managed through an observation stay. Despite their observation status, IMPACT classified $46.4 \%$ as high-risk for early mortality and $33.3 \%$ had $\geq 1$ high-risk characteristic. Co-morbid heart failure, renal or liver disease, high-risk for major bleeding, cancer and hemodynamic instability were low (each $<4.5 \%$ ), but $7.8 \%$ were $>80$ years-of-age and $19.4 \%$ had chronic lung disease.

Conclusion: Many PE patients selected for management in observation stay units appeared to have clinical characteristics suggestive of higher-risk for mortality based upon published claims-based and clinical risk stratification criteria.

Keywords: Pulmonary embolism, Observation stays, Resource utilization, Mortality

\section{Background}

Current guidelines suggest low-risk pulmonary embolism (PE) patients are candidates for treatment at home or with an abbreviated hospital stay versus $\sim 5+$ days of in-hospital management [1]. Prior studies suggest up to $50 \%$ of PE patients may be treated in such a fashion [2].

In the United States (US), observation stays are intended to manage patients for short periods to determine

\footnotetext{
*Correspondence: craig.coleman@hhchealth.org

'University of Connecticut School of Pharmacy, 69 North Eagleville Road,

Unit 3092, Storrs, CT 06269, USA

Full list of author information is available at the end of the article
}

appropriateness for inpatient admission, with the determination of admission/discharge occurring within 2midnights. Observation stays may serve as an alternative to inpatient management for low-risk PE patients. Reimbursement policy changes have led to an increasing use of observation stays [3-6]. We assessed agreement between observation management of $\mathrm{PE}$ and claims-based and clinical risk stratification criteria using administrative claims data. 


\section{Methods}

We performed a retrospective analysis using Premier claims data from $11 / 2012$ to $3 / 2015$. Premier captures $\sim 20 \%$ of all discharges from US acute care hospitals. This study was performed in accordance with the Declaration of Helsinki. All data included in the Premier Perspective Comparative Hospital Database are de-identified and are in compliance with the Health Insurance Portability and Accountability Act (HIPAA) of 1996 to preserve participant anonymity and confidentiality. For this reason, this study was exempt from institutional review board oversight and did not require an approval by an ethics committee. The data used in this study was under license from Premier Inc. and provided through the study sponsor, Janssen Scientific Affairs, LLC.

To be included, adult patients had to have undergone an observation stay (self-reported by hospitals) with an International Classification of Diseases, $9^{\text {th }}$-revision (ICD-9) diagnosis code for PE (415.1x) in the primary position, have a claim for $\geq 1$ diagnostic test for $\mathrm{PE}$ on day 0-2 (computed tomography, ventilation-perfusion scan, pulmonary angiography) and received pharmacologic (anticoagulation, thrombolysis) and/or non-pharmacologic (pulmonary embolectomy, filter placement) PE treatment [1].

Patient risk for early post-PE mortality was assessed using the validated In-hospital Mortality for PulmonAry embolism using Claims daTa (IMPACT) equation $[1 /(1+$ $\exp (-\mathrm{x})) ; \quad \mathrm{x}=-5.833+(0.026 \times$ age $)+(0.402 \times$ myocardial infarction $)+(0.368 \times$ chronic lung disease $)+(0.464 \times$ stroke $)+(0.638 \times$ prior major bleeding $)+(0.298 \times$ atrial fibrillation $)+(1.061 \times$ cognitive impairment $)+(0.554 \times$ heart failure $)+(0.364 \times$ renal failure $)+(0.484 \times$ liver disease $)+(0.523 \times$ coagulopathy $)+(1.068 \times$ cancer $)]$, with an estimated in-hospital mortality risk $>1.5 \%$ deemed higher-risk [7-9]. We also determined the proportion of patients with characteristics placing them at higher-risk for early mortality or other complications included in the simplified PE severity index (sPESI) or Hestia criteria (age $>80$ years, heart failure, chronic lung disease, renal impairment, liver disease, high-risk for major bleeding, cancer or a need for early thrombolysis/embolectomy [proxy for hemodynamic instability]) when assessable in the claims database $[10,11]$.

IMPACT mortality risk and patient characteristics were summarized using descriptive statistics. Percentages and means \pm standard deviations or medians (25\%, $75 \%$ range) were used to summarize categorical and continuous data. Statistical analysis was performed in IBM SPSS v22 (IBM Corp., Armonk, NY, USA).

\section{Results}

In total, 47,607 hospital encounters for PE were identified and $3.4 \%$ were coded as observation stays. Using
IMPACT, $\sim 46 \%$ of observation stay patients were at higher-risk for early post-PE mortality (Table 1). Over one-third of PE patients managed via an observation stay had $\geq 1$ criteria placing them at high-risk for early mortality. The proportion of patients with co-morbid heart failure, renal or liver disease, high-risk for major bleeding, cancer and requiring thrombolysis/pulmonary embolectomy were low $(<4.5 \%$ for each), but $7.8 \%$ patients were $>80$ years-ofage and $19.4 \%$ had chronic lung disease. One patient died during hospitalization (out-of-hospital mortality is not available in Premier) and 28\% stayed $>2$-midnights. Highrisk patients by IMPACT or those with $\geq 1$ high-risk criteria had longer length-of-stay ( $p \leq 0.005$ for both using a generalized linear model with a gamma distribution and log-link).

\section{Discussion}

Our study suggest anywhere from one-third to about half of PE patients managed via an observation stay in the US would be classified as higher-risk for early postPE mortality according to claims-based or clinical risk stratification criteria [7-11]. Advanced age and chronic lung disease were the most frequent "high-risk" characteristics identified in observation stay-managed patients.

The substantial proportion of observation stay patients in our study classified at higher-risk by IMPACT and select components of the sPESI and the Hestia criteria highlights the lack of agreement between US observation management of PE and risk stratification tools. Whether this observed disagreement suggests inappropriate use of observation stays is unknown. It does suggest; however, that risk stratification tools may be used infrequently by practitioners in routine practice [12-14]. Studies have reported common clinician barriers to using risk stratification tools including difficulties in implementation in routine practice $[12,13]$, lack of training in their use, regulatory constraints and the nature of the physicianpatient relationship [14]. Also of concern, risk stratification tools tend to oversimplify risk assessment (accurately identifying those at very low-risk, but classify a large majority who inevitably do not experience a complication as higher-risk) [12]. This overall lack of prognostic accuracy likely explains some inconsistencies between tool recommendations and clinical gestalt.

Whether clinical gestalt alone is optimal for identifying PE patients suitable for abbreviated stays is unclear. In a meta-analysis by Piran et al. [15], the pooled risk of recurrent venous thromboembolism in outpatient-treated $\mathrm{PE}$ patients was shown not to differ between clinical gestalt and risk stratification methods (1.9\% vs. $1.4 \%)$. Of note, nearly all studies examined in this meta-analysis were conducted in non-US centers decreasing its generalizability to US practice. Future studies to determine the prognostic 
Table 1 Characteristics of pulmonary embolism patients managed through observation stays

\begin{tabular}{|c|c|c|c|c|}
\hline Characteristic & $\begin{array}{l}\text { IMPACT low-risk } \\
\text { patients, n (\%) } \\
N=876\end{array}$ & $\begin{array}{l}\text { IMPACT higher-risk } \\
\text { patients, n (\%) } \\
N=757\end{array}$ & $\begin{array}{l}\text { No high-risk criteria } \\
\text { patients, n (\%) } \\
N=1,090\end{array}$ & $\begin{array}{l}\geq 1 \text { High-risk criteria } \\
\text { patients, n (\%) } \\
N=543\end{array}$ \\
\hline Age $($ mean $\pm S D)$ & $43.7 \pm 12.3$ & $70.1 \pm 10.7$ & $52.3 \pm 15.8$ & $63.4 \pm 18.5$ \\
\hline Male gender & $385(43.9)$ & $340(44.9)$ & $503(46.1)$ & $222(40.9)$ \\
\hline \multicolumn{5}{|c|}{ High-risk criteria included in sPESI or Hestia criteria } \\
\hline Age $>80$ years & $0(0)$ & $127(16.8)$ & $0(0)$ & $127(23.4)$ \\
\hline Heart failure & $4(0.5)$ & $68(9.0)$ & $0(0)$ & $72(13.3)$ \\
\hline Chronic lung disease & $91(10.4)$ & $226(29.9)$ & $0(0)$ & $317(58.4)$ \\
\hline Renal impairment & $3(0.3)$ & $67(8.9)$ & $0(0)$ & $70(12.9)$ \\
\hline Severe liver disease & $6(0.7)$ & $23(3.0)$ & $0(0)$ & $29(5.3)$ \\
\hline $\begin{array}{l}\text { High risk for major } \\
\text { bleeding }^{\mathrm{a}}\end{array}$ & $1(0.1)$ & $9(1.2)$ & $0(0)$ & $10(1.8)$ \\
\hline Cancer & $0(0)$ & $46(6.1)$ & $0(0)$ & $46(8.5)$ \\
\hline $\begin{array}{l}\text { Required thrombolysis or } \\
\text { embolectomy (days 0-2) }\end{array}$ & $2(0.2)$ & $2(0.3)$ & $0(0)$ & $4(0.7)$ \\
\hline $\begin{array}{l}\text { Estimated IMPACT }{ }^{\mathrm{b}} \text { mortality } \\
\text { risk, \% (mean } \pm \mathrm{SD})\end{array}$ & $1.0 \pm 0.3$ & $3.2 \pm 2.5$ & $1.3 \pm 0.7$ & $3.4 \pm 2.9$ \\
\hline Myocardial infarction & $1(0.1)$ & $0(0)$ & $0(0)$ & $1(0.2)$ \\
\hline Stroke & $0(0)$ & $2(0.3)$ & $0(0)$ & $2(0.4)$ \\
\hline Atrial Fibrillation & $3(0.3)$ & $85(11.2)$ & $31(2.8)$ & $57(10.5)$ \\
\hline Cognitive impairment & $0(0)$ & $57(7.5)$ & $14(1.3)$ & $43(7.9)$ \\
\hline Coagulopathy & $1(0.1)$ & $35(4.6)$ & $18(1.7)$ & $18(3.3)$ \\
\hline $\begin{array}{l}\text { Length of stay, days } \\
\text { (mean } \pm \text { SD) } \\
\text { (median }[25 \%, 75 \% \text { range]) }\end{array}$ & $\begin{array}{l}2.1 \pm 0.8 \\
2.0(2.0,3.0)\end{array}$ & $\begin{array}{l}2.4 \pm 1.6 \\
2.0(2.0,3.0)\end{array}$ & $\begin{array}{l}2.2 \pm 1.3 \\
2.0(2.0,3.0)\end{array}$ & $\begin{array}{l}2.3 \pm 1.0 \\
2.0(2.0,3.0)\end{array}$ \\
\hline
\end{tabular}

IMPACT In-hospital Mortality for PulmonAry embolism using Claims daTa, SD standard deviation, sPESI simplified pulmonary embolism severity index

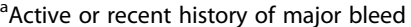

${ }^{\mathrm{b}}$ The multivariable IMPACT equation is: $1 /\left(1+\exp (-\mathrm{x})\right.$; where $\mathrm{x}=-5.833+\left(0.026^{*}\right.$ age $)+\left(0.402^{*}\right.$ myocardial infarction $)+\left(0.368^{*} \mathrm{chronic}\right.$ lung disease $)+\left(0.464^{*}\right.$ stroke $)$

$+\left(0.638^{*}\right.$ prior major bleeding $)+\left(0.298^{*}\right.$ atrial fibrillation $)+\left(1.061^{*}\right.$ cognitive impairment $)+\left(0.554^{*}\right.$ heart failure $)+\left(0.364^{*}\right.$ renal failure $)+\left(0.484^{*}\right.$ liver disease $)$

$+\left(0.523^{*}\right.$ coagulopathy $)+\left(1.068^{*}\right.$ cancer $)$

accuracy of clinical gestalt in comparison to accepted risk stratification tools are needed.

Our study has limitations worth noting. First, Premier does not provide access to clinical data including vital signs (e.g., blood pressure, heart or respiratory rate, oxygen saturation), out-of-hospital mortality or clot burden. Thus, we could not apply commonly used clinical criteria, tools such as PESI or assess all criteria included in the sPESI and Hestia tools. Inclusion of these data could have only increased the percentage of patients classified as higher-risk, and as a result, we likely underestimated the percentage of patients at high-risk of early post-PE mortality. However, nearly half of observation stay patients in our analysis were identified as high-risk according to the IMPACT equation, which was specifically designed for identification of low-risk PE patients using claims data and shown to have similar prognostic accuracy for both in-hospital and 30-day mortality as PESI, sPESI and Hestia [7-9]. Second, we did not have 30-day mortality data available and therefore cannot comment on whether these observation stay and higher-risk patients had subsequent adverse outcomes after discharge. Finally, since the overall proportion of patients being managed through observations stays in the US is limited, it is possible that other unidentified factors (e.g., societal or economic) are influencing the generalizability of these findings.

\section{Conclusion}

Our analysis suggests patient selection for abbreviated stays is not consistent with claims-based risk stratification tools and accepted clinical criteria denoting higherrisk for early mortality.

\section{Abbreviations}

ICD-9: International Classification of Diseases $9^{\text {th }}$-revision; IMPACT: In-hospital Mortality for PulmonAry embolism using Claims daTa; PE: Pulmonary embolism; SPESI: Simplified pulmonary embolism severity index; US: United States

Acknowledgements

Not applicable. 


\section{Funding}

This study was funded by Janssen Scientific Affairs, LLC, Raritan, NJ, USA.

\section{Availability of data and materials}

The data supporting the findings of this study are available from Premier Inc. but restrictions apply to the availability of these data, which were used under license for the current study, and so are not publicly available. Data are however available from the authors upon reasonable request and with permission of Premier Inc. The data used in this study was under license from Premier Inc. and provided through the study sponsor, Janssen Scientific Affairs, LLC.

\section{Authors' contributions}

Study concept and design: EN, CIC, WFP, ERW, VA, CC, JRS, TJB, GJF. Acquisition of data: EN, CIC, VA, CC, JRS. Analysis and interpretation of data: EN, CIC, WFP, PSW, ERW, VA, CC, PW, JRS, TJB, GJF. Drafting of the manuscript: EN, CIC. Critical revision of the manuscript for important intellectual content: EN, CIC, WFP, PSW, ERW, VA, CC, PW, JRS, TJB, GJF. Administrative, technical, or material support: EN, CIC, ERW, TJB, VA. Study supervision: CIC. EN, CIC and TJB had full access to all the data in the study and take responsibility for the integrity of the data and the accuracy of the data analysis. All authors read and approved the final manuscript. The authors meet criteria for authorship as recommended by the International Committee of Medical Journal Editors (ICJME) and were fully responsible for all content and editorial decisions, and were involved in all stages of manuscript development.

\section{Competing interests}

Dr. Coleman has received grant funding and consultancy fees from Janssen Pharmaceuticals; Bayer Pharma AG and Boehringer-Ingelheim Pharmaceuticals, Inc. Dr. Peacock has received grant funding and consultancy fees from Janssen Pharmaceuticals and Portola. Dr. Wells has received grant funding from Bristol Myers Squib and Pfizer, is on the advisory board and has received speaker's fees from Bayer Healthcare, has received consultancy fees from Janssen Pharmaceuticals, and served on a writing committee with Itreas. Ms. Ashton and Drs. Crivera, Schein, and Wildgoose are employees of Janssen Scientific Affairs LLC. Dr. Fermann has received grant funding for Pfizer and is on the advisory board and speaker's bureau for Janssen Pharmaceuticals. Drs. Nguyen, Weeda and Bunz have no competing interests germane to this article to report.

\section{Consent for publication}

Not applicable.

\section{Ethics approval and consent to participate}

This study was performed in accordance with the Declaration of Helsinki. All data included in the Premier Perspective Comparative Hospital Database are de-identified and are in compliance with the Health Insurance Portability and Accountability Act (HIPAA) of 1996 to preserve participant anonymity and confidentiality. For this reason, this study was exempt from institutional review board oversight and did not require an approval by an ethics committee. The data used in this study was under license from Premier Inc. and provided through the study sponsor, Janssen Scientific Affairs, LLC.

\section{Author details}

'University of Connecticut School of Pharmacy, 69 North Eagleville Road, Unit 3092, Storrs, CT 06269, USA. ²Department of Emergency Medicine, Baylor College of Medicine, 1504 Taub Loop, Houston, TX, USA. ${ }^{3}$ Department of Medicine, University of Ottawa, Ottawa Hospital Research Institute, 501 Smyth Road, Box 206, Ottawa, ON, Canada. ${ }^{4}$ Janssen Scientific Affairs, LLC, 1000 Route 202, Raritan, NJ, USA. ${ }^{5}$ New England Health Analytics, LLC, Granby, CT, USA. ${ }^{6}$ Department of Emergency Medicine, University of Cincinnati, 231 Albert Sabin Way, Cincinnati, OH, USA.

Received: 11 June 2016 Accepted: 2 February 2017

\section{Published online: 13 February 2017}

\section{References}

1. Kearon C, Akl EA, Ornelas J, et al. Antithrombotic therapy for VTE disease: CHEST guideline and expert panel review. Chest. 2016;149:315-52.

2. Baglin T. Fifty per cent of patients with pulmonary embolism can be treated as outpatients. J Throm Haemost. 2010;8:2404-5.
3. Sheehy AM, Graf BK, Gangireddy S, Formisano R, Jacobs EA. Observation status: for hospitalized patients: implications of a proposed Medicare rules change. JAMA Intern Med. 2013;173:2004-6.

4. Wright S. Memorandum report: hospitals' use of observation stays and short inpatient stays for Medicare beneficiaries, OEI-02-12-00040. Washington DC: United States Department of Health and Human Services, Office of Inspector General; 2013. [Accessed 4 Mar 2016]. Available from: http://oig. hhs.gov/oei/reports/oei-02-12-00040.pdf.

5. Feng Z, Wright B, Mor V. Sharp rise in Medicare enrollees being held in hospitals for observation raises concerns about causes and consequences. Health Aff. 2012;31:1251-9.

6. Overman RA, Freburger JK, Assimon MM, Li X, Brookhart MA. Observation stays in administrative claims databases: underestimation of hospitalized cases. Pharmacoepidemiol Drug Saf. 2014;23:902-10.

7. Coleman Cl, Kohn CG, Bunz TJ. Derivation and validation of the In-hospital Mortality for PulmonAry embolism using Claims daTa (IMPACT) prediction rule. Curr Med Res Opin. 2015;31:1461-8.

8. Coleman Cl, Kohn CG, Crivera C, Schein JR, Peacock WF. Validation of the multivariable In-hospital Mortality for PulmonAry embolism using Claims data (IMPACT) prediction rule within an all-payer inpatient administrative claims database. BMJ Open. 2015;5:e009251.

9. Weeda ER, Kohn CG, Fermann GJ, et al. External validation of prognostic rules for early post-pulmonary embolism mortality: assessment of a claims-based and three clinical-based approaches. Thromb J. 2016;14:7.

10. Jimenez D, Aujesky D, Moores L, RIETE Investigators, et al. Simplification of the pulmonary embolism severity index for prognostication in patients with acute symptomatic pulmonary embolism. Arch Intern Med. 2010;170:1383-9.

11. Zondag W, den Exter PL, Crobach MJ, Hestia Study Investigators, et al. Comparison of two methods for selection of out of hospital treatment in patients with acute pulmonary embolism. Thromb Haemost. 2013;109:47-52.

12. Eichler K, Zoller M, Tschudi P, Steurer J. Barriers to apply cardiovascular prediction rules in primary care: a postal survey. BMC Fam Pract. 2007;8:1.

13. Graham ID, Logan J, Bennett CL, et al. Physicians' intentions and use of three patient decision aids. BMC Med Inform Decis Mak. 2007;7:20.

14. Muller-Riemenschneider F, Holmberg C, Rieckmann N, et al. Barriers to routine risk-score use for healthy primary care patients: survey and qualitative study. Arch Intern Med. 2010:170:719-24.

15. Piran S, Le Gal G, Wells PS, et al. Outpatient treatment of symptomatic pulmonary embolism: a systematic review and meta-analysis. Thromb Res. 2013;132:515-9.

\section{Submit your next manuscript to BioMed Central and we will help you at every step:}

- We accept pre-submission inquiries

- Our selector tool helps you to find the most relevant journal

- We provide round the clock customer support

- Convenient online submission

- Thorough peer review

- Inclusion in PubMed and all major indexing services

- Maximum visibility for your research

Submit your manuscript at www.biomedcentral.com/submit
Biomed Central 